\title{
Long non-coding RNAs in osteosarcoma
}

\author{
Ruiling Chen ${ }^{1, *}$, Gangyang Wang ${ }^{1, *}$, Ying Zheng ${ }^{1}$, Yingqi Hua ${ }^{1}$ and Zhengdong Cai ${ }^{1}$ \\ ${ }^{1}$ Department of Orthopaedics, Shanghai Bone Tumor Institute, Shanghai General Hospital, Shanghai Jiao Tong University \\ School of Medicine, Shanghai, China \\ * These authors have contributed equally to this work \\ Correspondence to: Zhengdong Cai, email: czd856@vip.163.com \\ Yingqi Hua, email: hua_yingqi@163.com
}

Keywords: osteosarcoma; IncRNA; pathogenesis; biomarkers; therapeutic targets

Received: October 12,2016 Accepted: January 09, $2017 \quad$ Published: January 18, 2017

\section{ABSTRACT}

Long non-coding RNAs (IncRNAs) with more than 200 nuleotides, have been explored to participate in various cancer types including osteosarcoma (OS), which is the most common kind of primary bone tumors with high morbidity in infants and adolescents. These oncogenic or tumor suppressive IncRNAs regulate OS pathogenesis, such as cell growth, proliferation, invasion, migration, metastasis and cell apoptosis, serve as independent prognostic biomarkers or play a significant role in multidrug resistance (MDR) in OS cells. In this review, we attempt to dissect the participation of IncRNAs in pathogenesis of OS and their potential clinical values, and also provide an outlook for viable biomarkers and therapeutic targets in oS.

\section{INTRODUCTION}

Osteosarcoma(OS) is the most common primary malignant bone tumor in childhood and adolescence, the incidence of which is about (1-3)/1000, 000 per year throughout the world, with highly aggressive and early systemic metastasis [1-4]. Approximately $10 \%-25 \%$ of patients occurred lung metastasis, meanwhile pulmonary damage is the most prominent reason for OS-caused death [5]. With the application of chemotherapeutics, the combination of surgery resection and multi-chemotherapy has clinically become a standard treatment strategy for almost all OS patients and significantly improved patients' survival [6]. The cure rates of OS patients with focal tumor are elevated from less than $20 \%$ before 1970 s to present levels of $65-75 \%$ [7-9], while only $11 \%-30 \%$ of patients with matastasitic OS can survive [10-13]. Besides, many OS patients present resistance to available chemotherapeutics and then die of widespread metastasis and tumor relapse, which is a significant obstacle for successful OS treatments [14]. Despite of great efforts to search for novel therapeutic approaches, the overall survival of patients with OS has reached a plateau in recent 30 years [15]. Till now, we have well understood the biological characteristic of OS, but there still exist a large scale of fuzzy regions in exploration of molecular mechanisms involved in OS origination, metastasis, and chemoresistance. Therefore, candidate molecules as diagnostic or prognostic biomarkers and therapeutic targets are expected to be identified and may profoundly improve therapeutic efficacy and clinical outcomes for patients with OS. Inspiringly, some long non-coding RNAs (lncRNAs) have recently been reported to exert a key role in OS.

LncRNAs are transcripts that are numerous and unable to translate proteins in the intracellular space. It has been revealed that more than $90 \%$ of the human genome DNA is thought to be transcribed, while only about $2 \%$ of it can encode proteins. Majority of these transcribed RNAs are termed as non-coding RNAs (ncRNAs) [16, 17]. According to their transcript length, ncRNAs can be classified into 2 groups: small non-coding RNAs (small ncRNAs) composed of less than 200 nucleotides and long non-coding RNAs (lncRNAs) consisting of more than 200 nucleotides. The small ncRNAs [18] which include microRNAs (miRNAs), small interfering RNAs (siRNAs), piwi-interacting RNAs, transfer RNAs, and some ribosomal RNA, have been reported to function in the tumorigenesis, metastasis and chemoresistance of OS [19, 20]. However, lncRNAs have gained much less attention. In that lncRNAs account for over $70 \%$ of ncRNAs [21], we may predict that they contain much more genetic information which is needed to be explored. Thus, more and more researchers set to seek for associated lncRNAs in the pathogenesis or drug resistance mechanisms of OS, in order to discover the unknown functions of lncRNAs. 
During recent few years, few but noteworthy studies concerning functions of lncRNAs in OS pathogenesis and drug resistance have successively been reported, which might provide valuable biomarkers for diagnosis or prognosis and show great promise for exploring novel therapeutic approaches based on IncRNAs. Therefore, great benefits will be brought to improve the quality of life and overall survival for patients with OS. The present review will dissect the involvement of lncRNAs in pathogenesis of OS and their potential clinical application, and show possible anticipation of viable biomarkers and therapeutic targets in OS.

\section{WHAT ARE THE LNCRNAS}

With over 200 nucleotides in length, lncRNAs are characteristic of lack of protein-coding ability and were originally discovered in the transcripts of mice. [22] Later on, they were found to have five different origins: (A) a protein-coding gene gains structural damage and is transformed into a lncRNA; (B) by chromosomal rearrangement, two non-transcribed regions are in juxtaposition and generate a lncRNA with multiple exons; (C)duplication of a noncoding gene through retrotransposition forms either a functional retrogene or a nonfunctional retropseudogene, both without encoding proteins; (D)two tandem duplication events give rise to the adjacent repeats within a noncoding RNA; and (E)insertion of a transposon composes a functional lncRNA (Figure 1)
[23]. Based on their location in regard to protein-coding genes, they can be divided as follows: intergenic lncRNAs (lincRNAs), intronic lncRNAs (antisense/sense), exonic IncRNAs (antisense/sense), and overlapping lncRNAs (antisense/sense) [24, 25]. Initially, they were considered as transcriptional "noise" due to numerous transcripts [26]. However, with in-depth studies in recent years, they have been found to possess plenty of biological functions, including gene expression regulation [23, 27] at the epigenetic, transcriptional and posttranscriptional levels, and involvement in various cellular processes, which contain proliferation, differentiation, cell cycle progression, growth and apoptosis [28, 29]. Recently, considerable researches have shown that lncRNAs, serving as pivotal regulators and acting as oncogenes or tumor suppressors, play a crucial role in many different types of cancers, with the capacity to participate in tumor development, metastasis and chemoresistance. [30-34]

\section{ROLES OF LNCRNAS IN OS PATHOGENESIS}

Ever-growing evidence has unraveled the roles of lncRNAs in the pathogenesis of multiple human diseases including osteoarthritis [35] and OS [36]. Jinping Li et al. are the first to explore the expression profile of lncRNAs in OS. In 9 human primary OSs and their paired adjacent noncancerous samples, they found a total number of 25,733 lncRNAs through microarray analysis, with 403
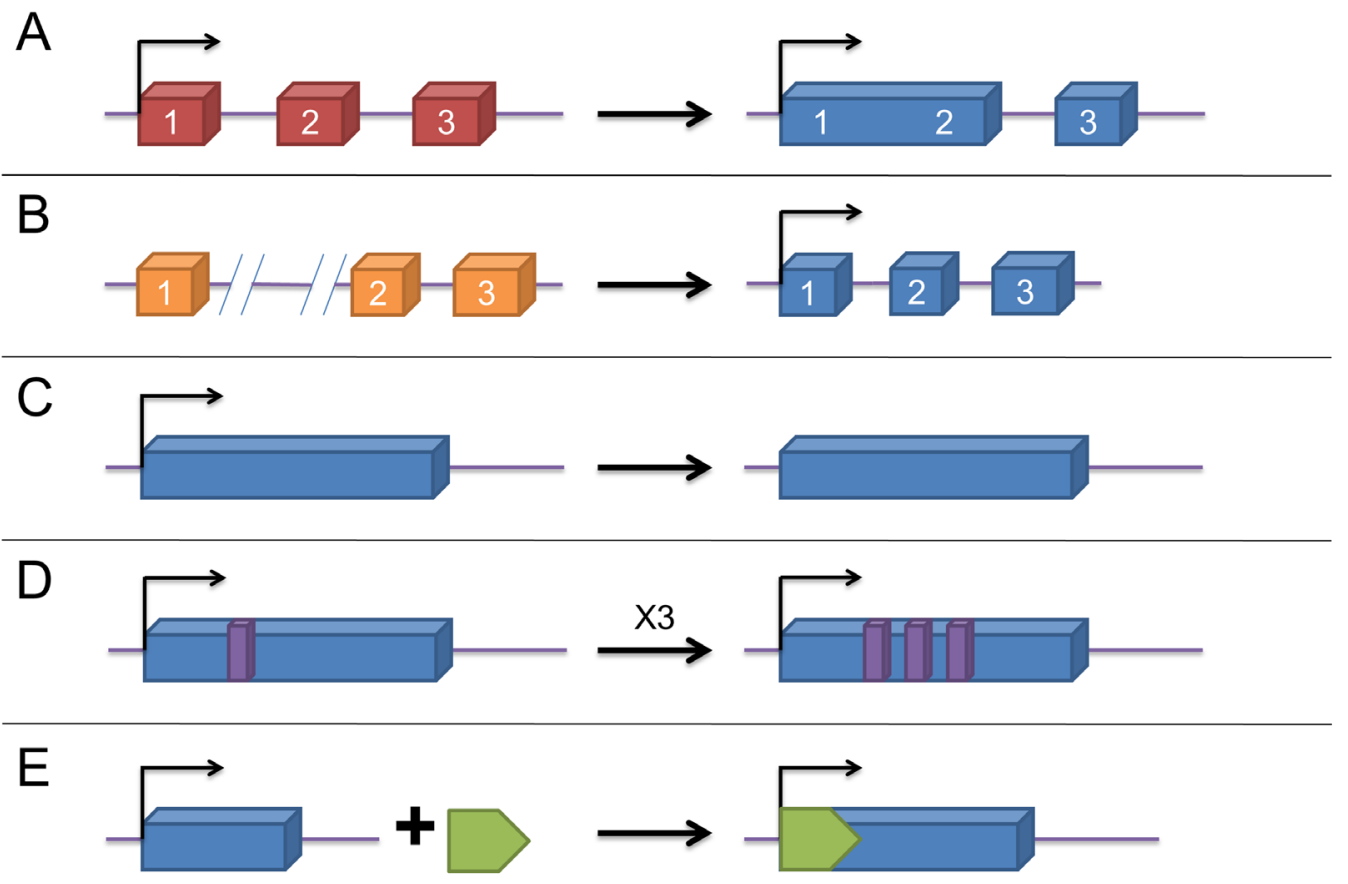

Figure 1: The origins of IncRNAs. A. a lncRNA is transformed from a protein-coding gene with structural damage; B. two abreast non-transcribed regions generate a lncRNA after chromosomal rearrangement; $\mathbf{C}$. copy of a noncoding gene by retrotransposition forms a lncRNA without protein-coding ability ; D. a lncRNA with adjacent repeats derives from tandem duplication events; E. a functional lncRNA with insertion of a transposon. 
Table 1: Roles and function mechanisms of IncRNAs in osteosarcoma

\begin{tabular}{|c|c|c|c|c|}
\hline LncRNA & Expression & Role of IncRNA & Function mechanism & Reference \\
\hline \multirow{4}{*}{ TUG1 } & \multirow{4}{*}{$\uparrow$} & $\begin{array}{l}\text { promotes cell proliferation, inhibits apoptosis, inhibits G0/G1 } \\
\text { cell cycle arrest }\end{array}$ & $\begin{array}{l}\text { sponges miR-9-5p:downregulates } P O U 2 F 1 \\
\text { expression }\end{array}$ & \multirow{4}{*}{$\begin{array}{l}{[29,49-51,} \\
87]\end{array}$} \\
\hline & & $\begin{array}{l}\text { associated with tumor size, clinical stage and post-operative } \\
\text { chemotherapy }\end{array}$ & downregulates $P O U 2 F 1$ expression & \\
\hline & & correlated with poor prognosis and disease status & & \\
\hline & & an independent prognostic indicator for overall survival & & \\
\hline HOTAIR & $\uparrow$ & $\begin{array}{l}\text { promotes cell proliferation, invasion and secrection of MMP2 } \\
\text { and MMP9 }\end{array}$ & - & {$[62,67,68]$} \\
\hline \multirow{4}{*}{ MALAT1 } & \multirow{4}{*}{$\uparrow$} & promotes cell proliferation and meatastasis & activates PI3K/AKT signaling pathway; & \multirow{4}{*}[53-56]{} \\
\hline & & & involvement of RhoA/ROCK Pathway & \\
\hline & & & MALAT1/MIR376A/TGFA axis & \\
\hline & & & regulated by Myc- 6 & \\
\hline \multirow{2}{*}{ H19 } & \multirow{2}{*}{$\uparrow$} & promotes cell proliferation, inhibites apoptosis & interacts with miR-141 & \multirow{2}{*}[60,61]{} \\
\hline & & induces osteosarcoma development & involvement of Hedgehog signaling & \\
\hline \multirow{2}{*}{ HULC } & \multirow{2}{*}{$\uparrow$} & $\begin{array}{l}\text { correlated with clinical stage, and distant metastasis, but not } \\
\text { in another study }\end{array}$ & - & \multirow{2}{*}[78,79]{} \\
\hline & & correlated with shorter overall survival & & \\
\hline SNHG12 & $\uparrow$ & promotes cell proliferation and migration & upregulates angiomotin gene expression & {$[45]$} \\
\hline MFI2 & $\uparrow$ & promotes cell proliferation, suppresses apoptosis & upregulates $F O X P 4$ expression & {$[46]$} \\
\hline PACER & $\uparrow$ & promotes cell proliferation and metastasis & activates $C O X-2$ gene in a NFkB-dependent way & {$[47]$} \\
\hline \multirow{2}{*}{ BCAR4 } & \multirow{2}{*}{$\uparrow$} & $\begin{array}{l}\text { correlated with large tumor size, advanced Enneking stage, } \\
\text { lung metastasis, }\end{array}$ & activates $G L I 2$-dependent gene transcription & \multirow{2}{*}[80]{} \\
\hline & & and poor prognosis & & \\
\hline $\begin{array}{l}\text { HNF1A- } \\
\text { AS1 }\end{array}$ & $\uparrow$ & $\begin{array}{l}\text { associated with clinical stage, distant metastasis, and poor } \\
\text { overall survival }\end{array}$ & activates $\mathrm{Wnt} / \beta$-catenin signaling pathway & {$[44]$} \\
\hline \multirow{2}{*}{ BANCR } & \multirow{2}{*}{$\uparrow$} & $\begin{array}{l}\text { associated with large tumor size, distant metastasis, and } \\
\text { advanced clinical stage }\end{array}$ & - & \multirow{2}{*}{$\begin{array}{l}{[27, \quad 86,} \\
110]\end{array}$} \\
\hline & & an independent predictor of poor survival & & \\
\hline \multirow{3}{*}{ UCA1 } & \multirow{3}{*}{$\uparrow$} & $\begin{array}{l}\text { correlated with large tumor size, high tumor grade, distant } \\
\text { metastasis, }\end{array}$ & - & \multirow{3}{*}[81]{} \\
\hline & & and advanced clinical stage & & \\
\hline & & an independent unfavorable prognostic factor & & \\
\hline \multirow{3}{*}{$91 \mathrm{H}$} & \multirow{3}{*}{$\uparrow$} & $\begin{array}{l}\text { correlated with advanced clinical stage, chemotherapy after } \\
\text { surgery, }\end{array}$ & - & \multirow{3}{*}[88]{} \\
\hline & & and tumor size $>5 \mathrm{~cm}$ & & \\
\hline & & an independent prognostic factor for overall survival & & \\
\hline ODRUL & $\uparrow$ & contributes to doxorubicin resistance & $\begin{array}{ll}\text { induces multidrug } & \text { resistance-related } \\
A B C B \text { lexpression } & \\
\end{array}$ & {$[77]$} \\
\hline \multirow{2}{*}{ HOTTIP } & \multirow{2}{*}{$\uparrow$} & $\begin{array}{l}\text { correlated with advanced clinical stage, distant metastasis and } \\
\text { poor prognosis }\end{array}$ & interacts with WDR5/MLL complex & \multirow{2}{*}{$\begin{array}{ll}{[83,} & 108, \\
109] & \end{array}$} \\
\hline & & increases cisplatin resistance & activates Wnt/ $\beta$-catenin signaling pathway & \\
\hline & & influences tumor angiogenesis and metastasis & $\begin{array}{lllll}\begin{array}{l}\text { upregulates } \\
\text { expression }\end{array} & A B C B 1, H I F 1 A \text { and } F O X C 2 \\
\end{array}$ & \\
\hline $\begin{array}{l}\mathrm{FUXC2-} \\
\mathrm{AS} 1\end{array}$ & $\uparrow$ & associated with poor chemoresponse and longer survival time & & {$[20]$} \\
\hline & & contributes to doxorubicin resistance & & \\
\hline LDTCO16 & & increases cisplatin-induced apoptosis & sponges endogenous miR-645 & {$[107$} \\
\hline LINC 00101 & 1 & reverses cisplatin resistance & upregulates IFIT2 & [101] \\
\hline & & promotes cell proliferation and migration & $\begin{array}{l}\text { binds and recruits } \mathrm{p} 300 \text { to the } Z E B 1 \text { promoter } \\
\text { region, }\end{array}$ & \\
\hline ZEB1-AS1 & $\uparrow$ & $\begin{array}{l}\text { correlated with large tumor size, progressed Enneking stage, } \\
\text { tumor metastasis, }\end{array}$ & activates $Z E B 1$ transcription & {$[48]$} \\
\hline & & worse recurrence-free and overall survival & & \\
\hline
\end{tabular}




\begin{tabular}{|c|c|c|c|c|}
\hline $\operatorname{loc} 285194$ & $\downarrow$ & promotes cell growth & induced by $p 53$,interact with miR- 211 & {$[70,71]$} \\
\hline MEG3 & $\downarrow$ & associated with poor overall survival & positively regulates $p 53$ expression & {$[84,85]$} \\
\hline TUSC7 & $\downarrow$ & $\begin{array}{l}\text { promotes cell proliferation and increases colony formation in } \\
\text { vitro }\end{array}$ & - & {$[43]$} \\
\hline \multirow{3}{*}{ HIF2PUT } & \multirow{3}{*}{$\downarrow$} & promotes cell proliferation and migration & positively correlated with $H I F-2 \alpha$ expression & \multirow{3}{*}{ [94] } \\
\hline & & decreases the percentage of CD133 expressing cells & & \\
\hline & & $\begin{array}{l}\text { impaires the osteosarcoma stem sphere-forming ability of the } \\
\text { MG63 cells }\end{array}$ & & \\
\hline
\end{tabular}

upregulated lncRNAs and 798 down-regulated lncRNAs. They further performed pathway analysis which indicated 34 pathways related to upregulated transcripts and 32 pathways related to downregulated transcripts [36]. Therefore, this study commendably hints the possible roles of lncRNAs as candidate biomarkers for diagnosis or prognosis and potential therapeutic targets in OS. However, the research progress of IncRNAs in OS is still preliminary, even though lncRNAs have become a hotspot of cancer researches in recent years and appealing progress has been made in lung cancer, breast cancer and gastric cancer, etc. [37-40] Excitingly, a small amout of oncogenic lncRNAs and tumor suppressive lncRNAs have been elucidated to be involved in the OS pathogenesis, including cell growth, proliferation, invasion, migration, metastasis and cell apoptosis. Herein, we summarize the known roles and functional mechanisms of the limited IncRNAs related to OS pathogenesis, which are shown in Table 1. These lncRNAs are found to function by several mechanisms: I) targeting some associated host genes like MFI2, SNHG12, PACER and BCAR4; II) involvement of signaling pathways like MALAT1, H19 and HOTTIP; III) competing endogenous RNA like TUG1, MALAT1 and H19, and so on. Intrestingly, TUG1, MEG3 and loc285194 were reported to be induced by $\mathrm{p} 53$ or regulate p53 expression in other diseases not in OS. However, it has been well illustrated that aberrations in p53 are common in OS [41], thus lncRNAs associated with p53 may be important regulators. Since both miRNA and lncRNAs can serve as oncogenes or tumor suppressors in OS [42], the interaction between IncRNAs and miRNAs implies the existence of competitive RNA regulatory network, which will further complement underlying molecular components in the pathogenesis of OS.

\section{LNCRNAS IN CELL GROWTH AND PROLIFERATION}

Recent studies have reported that aberrant expression of lncRNAs led to OS cell growth and proliferation, and then facilitated OS tumorigenesis. These findings show great promise for these lncRNAs to be potential therapeutic targets for OS treatments. For instance, inhibition of tumor suppressor lncRNA TUSC7 (tumor suppressor candidate 7, TUSC7) could promote
OS cell proliferation and enhance colony formation in vitro [43]. Down expression of HNF1A-AS1 (HNF1Aantisense 1, HNF1A-AS1), inhibited cell proliferation via inactivating $\mathrm{Wnt} / \beta$-catenin pathway in OS cells [44]. Besides, some lncRNAs are found to induce OS by a mechanism of targeting associated host genes. SNHG12 (small nucleolar RNA host gene 12, SNHG12), an oncogenic IncRNA, functions in cell proliferation by upregulating expression of angiomotin gene in human OS cells [45]. MFI2 (modified frailty index 2, MFI2) plays a positive role in occurrence and development of OS by enhancing FOXP4 (forkhead box P4, FOXP4) expression [46]. PACER (P50-associated COX-2 extragenic RNA, PACER), which is regulated by DNA methylation, promotes cell proliferation in OS via NFkB-dependent activation of COX-2 gene [47]. Oncogenic lncRNA ZEB1AS1 (ZEB1 Antisense 1, ZEB1-AS1) contributes to OS cells proliferation by activating ZEB1 transcription [48].

TUG1 (Taurine Up-regulated Gene 1, TUG1), a $6.7 \mathrm{~kb} \operatorname{lncRNA}$ located at $22 \mathrm{q} 12.2$, was previously suggested to be induced by p53, couple with PRC2 (polycomb repressive complex 2), and play a role in suppressing specific genes to regulate cell cycle [49]. Later on, significantly higher TUG1 levels were detected by Qiang Zhang et al. in 19 cases of OS tissues compared with matched adjacent non-tumorous tissues, and inhibition of TUG1 expression distinctly impaired proliferation of OS cells $[29,50]$. Importantly, the underlying molecular mechanism of TUG1 was demonstrated in a recent article, in which TUG1 inhibited G0/G1 cell cycle arrest and facilated OS tumorigenesis via sponging miR-9$5 \mathrm{p}$ and decreasing POU2F1 (POU class 2 homeobox 1, POU2F1) expression [51], which supports the existence of competitive RNA regulatory network.

MALAT1 (metastasis-associated lung adenocarcinoma transcript 1, MALAT1), a 8708nt lncRNA located at 11q13.1, was first identified in non-small cell lung cancer by Ji et al. in 2003 [52]. Taniguchi $\mathrm{M}$ et al. pointed out that Myc-6 may serve as a tumor suppressor in human OS cells partly by specifically down-regulating MALAT1, implying the potential role of MALAT1 in OS development [53]. Subsequently, Dong Y et al. reported that MALAT1 played an oncogenic role to promote cell growth in OS, probably by activating PI3K/AKT signaling pathway [54]. Additionally, RhoA/ROCK Pathway was revealed to involve in the MALAT1-mediated occurrence 
of OS [55]. Interestingly, Wei Luo et al. discovered the involvement of miRNA in MALAT1-mediated OS. They elucidated a MALAT1/MIR376A/TGFA (transforming growth factor alpha, TGFA) axis participating in OS progression, in which MALAT1 promoted OS development by acting as endogenous miRNA sponges to repress MIR376A and increase TGFA expression [56]. These findings indicate the significant function of interaction between IncRNAs and miRNAs.

H19, a 6295nt lncRNA, lies in an imprinted region of chromosome 11 and is adjacent to IGF2 (insulin-like growth factor 2, IGF2) gene which includes a miR-675 in exon one [57]. It has been reported that lncRNA H19 can play either oncogenic or tumor suppressive role in the progression of diverse cancers [58, 59]. Recently, H19 has been discovered to be involved in the pathogenesis mechanism of OS and may serve as an oncogenic lncRNA. Chan LH et al. demonstrated that IncRNA H19 is overexpressed by the up-regulation of Hedgehog signaling and overexpression of Yap1, and the aberrant Hedgehog signaling contributes to the tumorigenesis of OS [60]. In another study, Peiheng $\mathrm{He}$ et al. revealed that overexpression of tumor suppressor miR-141 inhibited osteoblastic cell proliferation through down-regulation of H19 or miR-675 in OS [61], which also illustrates the interaction of endogenous miRNAs with lncRNAs.

HOTAIR (HOX transcript antisense RNA, HOTAIR), a 2337nt lncRNA located at 12q13.13, has a high expression in OS tumor tissues, and notably promotes tumor growth [62]. With better study in many other types of cancers including ovarian cancer [63], hepatocellular carcinoma [64], lung cancer [65] and breast cancer [66], HOTAIR was reported to have a role as a molecular scaffold binding PRC2 through the 5' domain and LSD1/ CoREST/REST complexes through the 3' domain, so as to participate in tumor development by promoting histone H3K27 trimethylation and inhibiting gene expression [67, 68]. But this action mechanism remains to be studied in OS. Additionally, rs7958904, a HOTAIR variant, was markedly associated with lower risk of OS in a two-stage, case-control study [69].

loc285194, located at osteo3q13.31 and acting as a tumor suppressor, was first reported lncRNA in OS by Pasic, I. et al. in 2010 [70]. However, the underlying

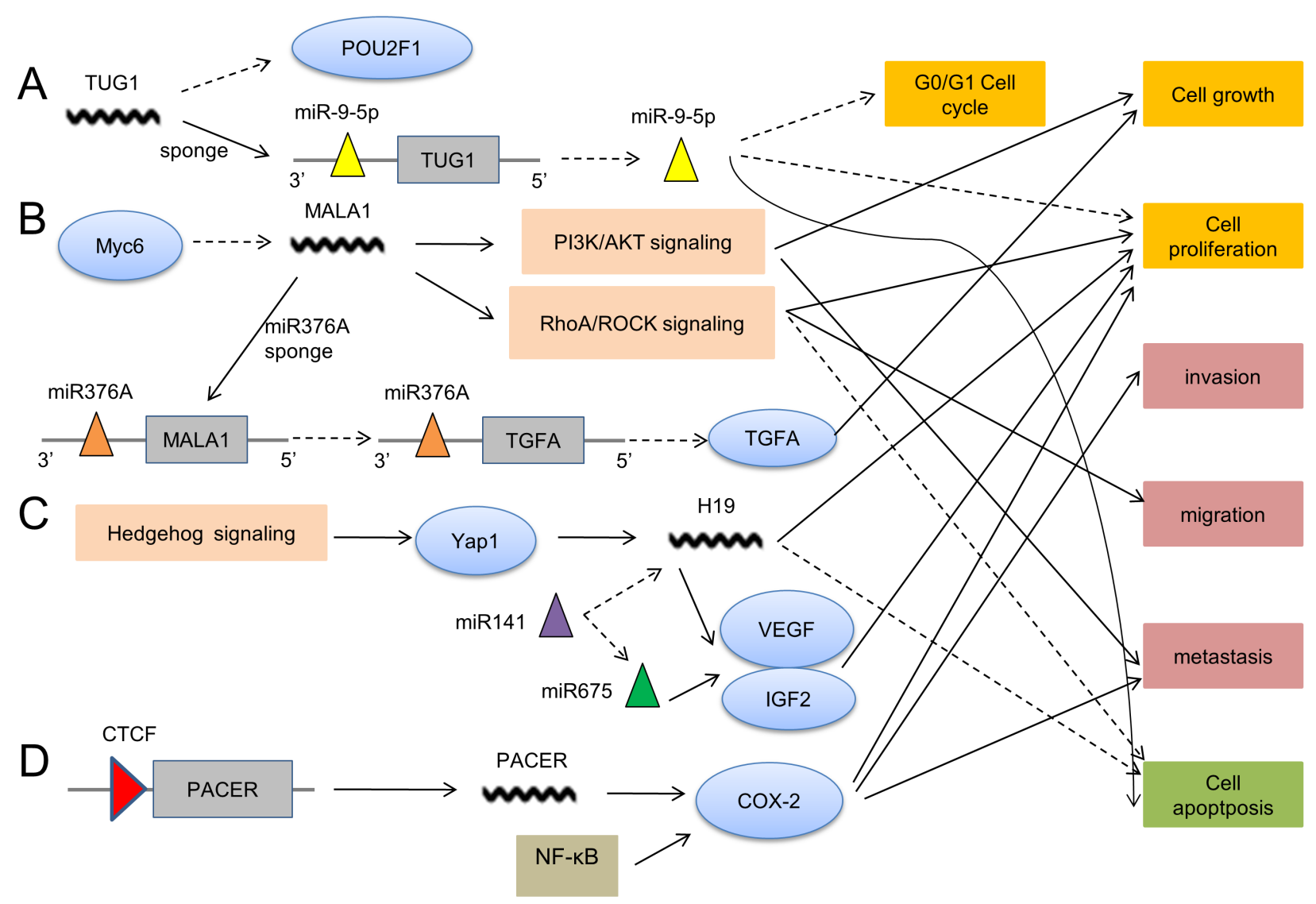

Figure 2: The action mechanisms of IncRNAs in OS pathogenesis. A. TUG1 decreases POU2F1 expression and sponges miR-9$5 \mathrm{p}$ to promote cell proliferation and cell cycle, but inhibits cell apoptosis. B. MALAT1 plays a role in OS pathogenesis via the involvement of PI3K/AKT signaling, RhoA/ROCK signaling and sponging miR376A. C. H19 is upregulated by Hedgehog signaling to facilitate cell proliferation and suppress apoptosis. H19 can also interact with miRNA. D. With the binding of CTCF (CCCTC-binding factor), PACER functions by targeting COX-2 which is also regulated by NF- $\mathrm{BB}$. 
mechanism of it in OS hasn't been reported. Later on, by using HCT-116 cells, Qian Liu et al. found that a p53regulated lncRNA loc285194 inhibits cell growth both in vitro and in vivo. The underlying mechanism of it in colon tumor is partly due to the negatively regulated miR-211and they further revealed a reciprocal suppression between loc285194 and miR-211 [71]. These results indicate the possible functional mechanisms of loc285194 in OS and in-depth exploration of loc285194 in OS is needed.

\section{LNCRNASININVASION,MIGRATIONAND METASTASIS}

Metastasis and relapse are principal pathological problems in the malignant progression of OS, which evidently hampers the effectiveness of OS clinical treatmets and brings unfavorable outcomes to OS patients. Acording to the statistics, $90 \%$ of OS patients occurred lung metastasis before the application of chemotherapeutics [72] while only $20 \%$ of patients with metastasis and recurrence at diagnosis could be cured even with multi-drug treatment [73]. Therefore, high rate of metastasis is a big challenge that should be solved for successful clinical treatments in OS. To achieve it, better understanding of underlying mechanism of tumor invasion, migration and metastasis is of great benefit. In recent years, lncRNAs have been reported to be involved in tumor invasion and metastasis, and presented a brilliant prospect in many different cancers including OS, which may provide valuable therapeutic targets and potential biomarkers for prognosis [74-76].

The expression of ODRUL (OS doxorubicinresistance related up-regulated IncRNA, ODRUL) was elevated in tumor tissues of OS patients with lung metastasis [77]. Increased HULC (highly up-regulated in liver cancer, HULC) was found to be associated with clinical stage and distant metastasis for OS patients by Xiaohui Sun et al. [78] On the contrary, it showed no potential functions of HULC in clinicopathological characteristics of OS patients in another study [79]. MALAT1 facilitates metastasis in OS, possibly through activation of PI3K/AKT signaling pathway [54]. High expression of HOTAIR notably promotes OS invasion by increasing the secretion of MMP2 and MMP9 [62]. SNHG12 functions in migration by elevating expression of angiomotin gene in human OS cells [45]. PACER promotes metastasis in OS via NFKB-dependent activation of COX-2 gene [47]. LncRNA MFI2 could promote

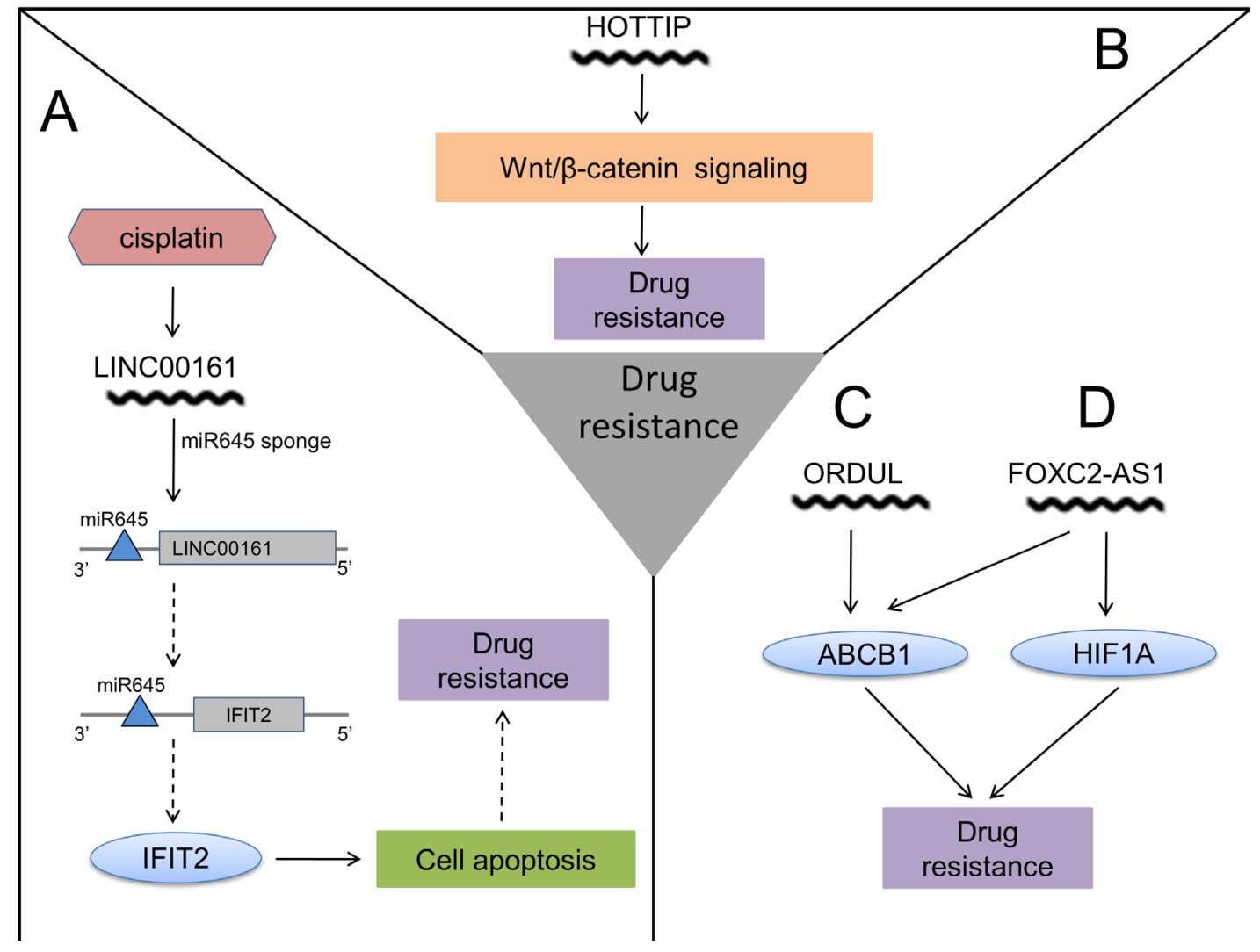

Figure 3: The action mechanisms of IncRNAs in OS chemoresistance. A. Cisplatin induces expression of LINC00161, which sponges miR645 to reverse drug resistance. B. HOTTIP contributes to drug resistance through activating Wnt $/ \beta$-catenin signaling. C. ORDUL increases drug resistance by elevating ABCB1. D. High expression of FOXC2-AS1 causes drug resistance with increased ABCB1 and HIF1A. (The solid arrow represents promoting and the dashed arrow represents inhibiting.) 
migration of OS cells through upregulating FOXP4 expression [46]. Markedly elevated BCAR4 (Breast Cancer Anti-Estrogen Resistance 4, BCAR4) is associated with lung metastasis by activation of transcription of GLI2-dependent gene [80]. Upregulated ZEB1-AS1 has connection with tumor metastasis in OS by the way of increasing ZEB1 expression [48]. Additionally, lncRNAs BANCR (BRAF-activated noncoding RNA, BANCR) [27], and UCA1 (urothelial carcinoma associated 1, UCA1) [81] are associated with distant metastasis and also identified as independent prognostic biomarkers for poor outcomes in OS.

\section{LNCRNAS IN CELL APOPTOSIS}

Induction of cancer cells apoptosis is the ultimate aim in cancer treatment. However, some malignant cancer cells may enhance their viability, reduce cell apoptosis, and then become drug resistant during diverse cancer drug treatments. These drug-resistant cancer cells then contribute to tumor origination and progression, which makes malignant cancers clinically intractable diseases. Some recent studies focusing on lncRNAs have demonstrated involvement of lncRNAs in OS cell apoptosis, which indicates latent therapeutic targets for effective clinical treatments.

Qiang Zhang et al. showed that suppressing expression of TUG1 significantly promoted OS cell apoptosis. [29, 50] Yin $\mathrm{Z}$ et al. found that lncRNA MFI2 could promote cell apoptosis by regulating FOXP4 expression. [46] Z.Q. Peng et al. discovered that inhibition of BANCR promoted MG-63 cell apoptosis in vitro in addition to suppressing cell proliferation and invasion. [27] Peiheng He et al. reported that high expression of miR-141 promoted cell apoptosis by reducing lncRNA H19 or miR-675 in OS. [61] In another study, Yunlu Liu et al. elucidated the effects of MALAT1 on cell apoptosis induction via the RhoA/ROCK pathway to facilitate the tumorigenesis of OS. [55]

Collectively, these lncRNAs facilitate development and progression of OS by participating in cell growth, proliferation, invasion, migration, metastasis and cell apoptosis. These study findings present potential clinical values of lncRNAs to be therapeutic targets for effective OS treatments. The concrete action mechanisms in many of them are still unexplored, thus in-depth studies remain to be performed.

\section{POTENTIAL UTILITY OF LNCRNAS IN OS}

\section{LncRNAs in OS diagnosis and prognosis}

In recent decades, the treatment effectiveness for OS patients hasn't been improved even with much more therapeutic choices. OS is apt to metastasis and recurrence, which causes unpleasant clinical outcomes. Early diagnosis and accurate prognosis may make it possible to take timely treatment and clear focus in the early stage, and thus have contribution to enhance the overall survival of OS patients. Therefore, appropriate biomarkers for diagnosis or prognosis have a great clinical significance. Research results about lncRNAs associated in OS indicate that lncRNAs may have potential clinical values as diagnostic or prognostic biomarkers.

Overexpression of lncRNA FGFR3-AS1 (Fibroblast Growth Factor 3 antisense transcript 1, FGFR3-AS1) is correlated with large tumor size, advanced Enneking stage, and poor survival [82]. Increased HOTTIP (HOXA transcript at the distal tip, HOTTIP) was recently discovered in human OS samples, connecting with advanced clinical stage, metastasis and poor prognosis. [83] As previously mentioned, there are contradictory results in clinicopathological characteristics of OS patients in two studies, but both studies demonstrated that overexpression of HULC was correlated with unfavorable clinical outcomes. [78, 79] Distinctly upregulated BCAR4 is associated with large tumor size, advanced clinical stage, and poor outcomes via activating transcription of GLI2-dependent gene. [80] Overexpressed ZEB1-AS1 has close relations to large tumor size, progressed Enneking stage, and poor overall survival in OS through activation of ZEB1 transcription [48]. Decreased lncRNA MEG3, which positively regulates the expression of p53 gene [84], was found to be correlated with unfavorable overall survival of OS. [85] Significantly higher expression of lncRNA FOXC2-AS1 was associated with longer survival time for OS patients. [20] These findings indicate the promising ability of lncRNAs to be possible biomarkers for prognosis in OS clinical treatments.

loc285194 was first discovered in OS but the underlying mechanism is totally unclear. However, Qian Liu et al. reported the low expression of loc285194 detected in colon tumor specimens, and indicated that loc285194 could be a diagnostic marker for colon cancer. [71] Therefore, the potential diagnostic role of loc 285194 in OS remains to be explored.

Additionally, some explored lncRNAs have been identified as independent prognostic biomarkers in OS. BANCR (BRAF-activated noncoding RNA, BANCR), which is $693 \mathrm{bp}$ in length, was initially discovered in melanoma cells by Flockhart et al. in 2012. [86] Elevated 
BANCR was markedly correlated with large tumor size, advanced clinical stage, distant metastasis and poor survival in OS and it was suggested by Z.Q. Peng et al. to be an independent predictor of poor prognosis. [27] TUG1 (Taurine Up-regulated Gene 1, TUG1), which was reported to be a possible therapeutic target in OS [50], also has close connection with disease status, for which plasma TUG1 may contribute to OS diagnosis, prognosis and dynamic surveillance. [87] Upregulated UCA1 (urothelial carcinoma associated 1, UCA1) could be connected with large tumor size, advanced clinical stage and distant metastasis, and serve as an independent prognostic biomarker for poor outcomes. [81] Increased expression of lncRNA 91H (antisense H19 transcript, 91H) not only was notably associated with large tumor size, advanced clinical stage and post-surgery chemotherapy, but also could be an independent predictive factor of poor survival for OS patients. [88] Higher expression of MALAT1 existed in OS patients with advanced clinical stage and distant metastasis, and contributed to a shorter survival time, which illustrates its potential as an independent prognostic factor to predict patients' survival situation [89].

\section{LncRNAs in OS chemotherapy}

The application of chemotherapy has provided revolutionary changes to the survival rate of OS patients. [90] However, there are still lots of OS patients having less sensitivity to current chemotherapeutics like doxorubicin and cisplatin, which subsequently results in poor clinical outcomes. [14] In recent three decades, the overall survival of OS patients seems to have stagnated, which urgently requires seeking for novel therapeutic targets and effective reversion of resistance to current therapeutic drugs.

As for novel therapeutic targets, researchers have made a tentative exploration in the involvement of lncRNAs in OS in recent years. These oncogenic or tumor suppressive lncRNAs that participate in OS pathogenesis, provide potential therapeutic targets for OS clinical treatments. For example, overexpressed HOTAIR in OS tumor tissues that markedly promotes tumor growth and metastasis [62], increased MALAT1 with involvement of signaling pathways and miRNA [54-56], down-regulated lncRNA TUSC7 associated with cell proliferation [43], elevated BCAR4 related to lung metastasis by regulating GLI2-dependent gene [80], and independent prognostic predictor BANCR [86] imply the possiblity of targeted therapy based on lncRNAs.

Cancer stem cells (CSCs) with stem cell-like properties, account for a small part in malignant cancers, but they take responsibility for cancer initiation and progression. [4, 91, 92] It is reported that CSCs also exist in OS and contribute to tumor invasion and relapse. [93] Therefore, treatments targeting at CSCs may obtain some unexpected improvements for OS patients. For achieving this, a good understanding of CSCs is absolutely needed.
Yongcheng Wang et al. were the first to explore the role of lncRNAs in CSCs. They demonstrated that upregulated HIF2PUT (hypoxia-inducible factor- $2 \alpha$ promoter upstream transcript, HIF2PUT) significantly suppressed cell proliferation and migration, reduced the percentage of CD133 expressing cells, and damaged the OS stem sphere-forming ability of the MG63 cells. Besides, HIF2PUT had positive relationship with the expression of $H I F-2 \alpha$. This study provides a hint that HIF2PUT may be a useful regulatory target of OS stem cells as well as a latent therapeutic target for OS treatments [94].

As for reversion of resistance to therapeutic drugs, plentiful studies have focused on exploring the underlying mechanisms of chemoresistance in OS by genetic and molecular analyses, and tremendous progress has been made. Findings from these studies present diverse biological alterations, including up-regulation of $\mathrm{ABC}$ membrane transporter family members, abnormal metabolic pathways, interference in cell cycle regulation and disorders of cell death pathways. [95-97] As a result, these changes can cause drug inactivation [98], reduced intracellular drug accumulation [99], cancer stem cell (CSC)-mediated chemoresistance [100, 101], disorders in signal transduction pathways [102], dysregulation of miRNAs $[103,104]$ as well as apoptosis- and autophagyrelated drug resistance $[105,106]$.

However, almost none of the currently available approaches can effectively reverse the poor chemoresponse in OS. Chemoresistance now extremely hampers the efficacy and improvement of clinical therapies for OS patients. Hence, better understanding of the underlying mechanism of chemoresistance from a new prospective may provide feasible methods to effectively reverse drug resistance in OS and improve overall survival of OS patients. In view of the existence of much more lncRNAs compared to miRNAs [21], research focus is shifted to their unclear functions. Therefore, despite of well-studied miRNAs in resistance to chemotherapeutics [103, 104], researchers recently have paid attention to the function of unexplored lncRNAs.

A recent study demonstrated that a distinctly higher expression of IncRNA ENST00000563280, which was named FOXC2-AS1 (FOXC2 antisense RNA 1, FOXC2AS1), was associated with poor chemoresponse for OS patients, implying its potential to be a novel predictor of chemoresponse. It was also revealed that FOXC2AS1 may have contribution to doxorubicin resistance by increasing the expression of some classical MDR (multidrug resistance) associated genes, including $A B C B$ land HIF1A. [20] Overexpression of ODRUL (OS doxorubicinresistance related up-regulated lncRNA, ODRUL) was shown in tumor tissues of OS patients with lung metastasis and a low chemoresponse. It was reported that lncRNA ODRUL may reduce sensitivity to doxorubicin in OS cells by inducing expression of $A B C B 1$, which is classically related to multidrug resistance. [77] LncRNA LINC00161 
(long intergenic non-coding RNA 161, LINC00161) was revealed to play an essential role in cisplatininduced apoptosis, and attenuate OS chemoresistance by targeting the miR-645-IFIT2 (interferon-induced with tetratricopeptide repeats 2, IFIT2) signaling axis. [107] Upregulated HOTTIP was recently discovered in human OS specimens, and associated with advanced clinical stage, metastasis and poor prognosis. [83] Previously, the action mechanism of HOTTIP was elucidated in Hirschsprung disease, in which HOTTIP interacted with WDR5/MLL complex to increase the expression of multiple 5' HOXA genes by enhancing histone $\mathrm{H} 3$ lysine 4 trimethylation. [108] But this mechanism hasn't been demonstrated in OS. Of note, HOTTIP also participated in OS cellular resistance to cisplatin by the activation of Wnt/ $\beta$-catenin signaling pathway, which indicates a potential therapeutic approach to targeting $\mathrm{Wnt} / \beta$-catenin signaling pathway to reverse the resistance. [109]

In summary, IncRNAs possess potential of serving as diagnostic or prognostic biomarkers, and providing viable therapeutic targets. Drug resistance associated lncRNAs directly connect drug resistance with intracellular MDR associated genes, signaling pathways and interaction with miRNA, which further complements and optimizes our present understanding of OS chemoresistance mechanisms. The clinical application of these lncRNAs still requires further identification and verification.

\section{SUMMARY AND PROSPECT}

This review summarizes results from recent studies of IncRNAs that act as oncogenes by overexpression or tumor suppressors by downexpression in OS, like HOTAIR, MALAT1, H19, TUG1, MEG3 and TUSC7. By serving as pivotal regulators, they participate in the pathogenesis process of OS, including cell growth, proliferation, invasion, migration, metastasis and cell prognosis. Several mechanisms are found from these lncRNAs, such as targeting some associated host genes, involvement of signaling pathways, competing endogenous RNA and so on. In addition, some lncRNAs are identified as independent prognostic biomarkers and some are involved in resistance to currently available chemotherapeutics like doxorubicin and cisplatin. These results show great promise for developing feasible diagnostic or prognostic biomarkers and prospective therapeutic targets based on lncRNAs. Further investigation and identification are still needed for these lncRNAs. Besides, in order to apply them to clinical diagnosis and treatment, it's inevitable to study the effects of them in human beings by carrying out large-scale clinical trials in the near future.

Despite of the above achievements, here we would also like to put forward some problems and puzzles based on these recent studies.
First, where can we get samples to detect lncRNAs for human OS patients? Clinically, it's difficult and inconvenient to obtain tumor tissues for early diagnosis and prognosis. Researchers commonly get tissue samples after surgery resections. Of note, a recent study detected plasma lncRNA TUG1and showed a strong correlation between the level of plasma lncRNA TUG1 and disease status. [87] We predict that liquid specimens, such as human peripheral blood, may commendably solve this problem and provide real-time dynamic surveillance. Besides, for patients with lung metastasis, sputum possibly becomes a better choice.

Second, overexpression of BANCR is detected in OS patients [27], but it's still positively associated with low viability of OS cells in a baicalein-treated process. [110] Baicalein, a bioactive flavonoid pervasively used in ancient China, was newly reported to have an effect on apoptosis, cell cycle arrest, migration and invasion of OS in 2013. [111] These contradictory findings may imply that BANCR can function by different mechanisms in different situations. Or maybe the increased BANCR in a baicaleintreated process aims to resist the effect of baicalein. To make it clear, further investigation of BANCR in OS is requested.

Third, whether lncRNAs can be induced in the process of treating therapeutic agents is needed to be identified. $17 \beta$-estradiol (E2) has been put forward to play a role in inhibition of OS cell proliferation since 1970s [112], but it hasn't been applied to OS clinical therapy. Recently, a study revealed that after treating with high dose of E2 in OS cells, the expression of miR-9 was elevated, which subsequently reduced the expression of MALAT1 at posttranscriptional level. [53] As mentioned earlier, MALAT1plays an oncogenic role in OS. [54] The decreased MALAT1 after E2 treatment and increased BANCR after baicalein treatment may lead to a guess that lncRNAs can be induced after treatment of therapeutic agents.

Though the above research findings present a good tendency of research development, the research progress of lncRNAs in OS is still preliminary. Therefore, much more time and efforts should be invested in exploring a more comprehensive mechanism of IncRNAs in OS pathogenesis, chemoresistance as well as therapeutic agents treatment. Researchers are confronted with numerous challenges, such as difficulty of obtaining substantial tumor specimens because of the low morbidity, extensive heterogeneity between or in tumor tissues and a fairly complex genetic background. Not until these challenges are overcome can we have a better understanding of molecular mechanisms in OS and achieve a goal of effectively improving overall survival of OS patients.

We anticipate that lncRNAs will be better studied in OS and play a crucial role in clinical diagnosis or prognosis and treatment of human OS before long. 
LncRNA-targeting therapies will offer unexpected and overwhelming benefits for OS patients.

\section{ACKNOWLEDGMENTS}

This work was supported by the National Natural Science Foundation (81202115). Shanghai Municipal Human Resources and Social Security Bureau(0403N14001), Shanghai Charity cancer research center (0703N14012), and ShanghaiScience and Technology Commission (14140904000).

\section{CONFLICTS OF INTEREST}

The authors declare no conflict of interest.

\section{REFERENCES}

1. Messerschmitt PJ, Garcia RM, Abdul-Karim FW, Greenfield EM, Getty PJ. Osteosarcoma. J Am Acad Orthop Surg. 2009; 17:515-27.

2. Bousquet M, Noirot C, Accadbled F, Sales de Gauzy J, Castex MP, Brousset P, Gomez-Brouchet A. Whole-exome sequencing in osteosarcoma reveals important heterogeneity of genetic alterations. Ann Oncol. 2016; 27:738-44.

3. Mirabello L, Troisi RJ, Savage SA. International osteosarcoma incidence patterns in children and adolescents, middle ages and elderly persons. Int J Cancer. 2009; 125:229-34.

4. Merlos-Suárez A, Barriga FM, Jung P, Iglesias M, Céspedes MV, Rossell D, Sevillano M, Hernando-Momblona X, da Silva-Diz V, Muñoz P, Clevers H, Sancho E, Mangues $\mathrm{R}$, Batlle E. The intestinal stem cell signature identifies colorectal cancer stem cells and predicts disease relapse. Cell Stem Cell. 2011; 8:511-24.

5. Miller BJ, Cram P, Lynch CF, Buckwalter JA. Risk factors for metastatic disease at presentation with osteosarcoma: an analysis of the SEER database. J Bone Joint Surg Am. 2013; 95:e89, 1-8.

6. Iwamoto $\mathrm{Y}$, Tanaka K, Isu K, Kawai A, Tatezaki S, Ishii T, Kushida K, Beppu Y, Usui M, Tateishi A, Furuse K, Minamizaki T, Kawaguchi N, Yamawaki S. Multiinstitutional phase II study of neoadjuvant chemotherapy for osteosarcoma (NECO study) in Japan: NECO-93J and NECO-95J. J Orthop Sci. 2009; 14:397404.

7. Eilber F, Giuliano A, Eckardt J, Patterson K, Moseley S, Goodnight J. Adjuvant chemotherapy for osteosarcoma: a randomized prospective trial. J Clin Oncol. 1987; 5:21-26.

8. Jaffe N. Osteosarcoma: review of the past, impact on the future. The American experience. Cancer Treat Res. 2009; 152:239-62.

9. Allison DC, Carney SC, Ahlmann ER, Hendifar A, Chawla S, Fedenko A, Angeles C and Menendez LR. A meta- analysis of osteosarcoma outcomes in the modern medical era. Sarcoma. 2012; 2012:704872.

10. Meyers PA, Heller G, Healey JH, Huvos A, Applewhite A, Sun M, LaQuaglia M. Osteogenic sarcoma with clinically detectable metastasis at initial presentation. J Clin Oncol. 1993; 11:449-53.

11. Kager L, Zoubek A, Pötschger U, Kastner U, Flege S, Kempf-Bielack B, Branscheid D, Kotz R, Salzer-Kuntschik M, Winkelmann W, Jundt G, Kabisch H, Reichardt P, et al, and Cooperative German-Austrian-Swiss Osteosarcoma Study Group. Primary metastatic osteosarcoma: presentation and outcome of patients treated on neoadjuvant Cooperative Osteosarcoma Study Group protocols. J Clin Oncol. 2003; 21:2011-18.

12. Chou AJ, Merola PR, Wexler LH, Gorlick RG, Vyas YM, Healey JH, LaQuaglia MP, Huvos AG, Meyers PA. Treatment of osteosarcoma at first recurrence after contemporary therapy: the Memorial Sloan-Kettering Cancer Center experience. Cancer. 2005; 104:2214-21.

13. Daw NC, Billups CA, Rodriguez-Galindo C, McCarville MB, Rao BN, Cain AM, Jenkins JJ, Neel MD, Meyer WH. Metastatic osteosarcoma. Cancer. 2006; 106:403-12.

14. Bennett JH, Thomas G, Evans AW, Speight PM. Osteosarcoma of the jaws: a 30-year retrospective review. Oral Surg Oral Med Oral Pathol Oral Radiol Endod. 2000; 90:323-32.

15. Xu H, Niu X, Zhang Q, Hao L, Ding Y, Liu W, Yao L. Synergistic antitumor efficacy by combining adriamycin with recombinant human endostatin in an osteosarcoma model. Oncol Lett. 2011; 2:773-78.

16. Djebali S, Davis CA, Merkel A, Dobin A, Lassmann T, Mortazavi A, Tanzer A, Lagarde J, Lin W, Schlesinger F, Xue C, Marinov GK, Khatun J, et al. Landscape of transcription in human cells. Nature. 2012; 489:101-08.

17. Martens-Uzunova ES, Böttcher R, Croce CM, Jenster G, Visakorpi T, Calin GA. Long noncoding RNA in prostate, bladder, and kidney cancer. Eur Urol. 2014; 65:1140-51.

18. Enfield KS, Pikor LA, Martinez VD and Lam WL. Mechanistic Roles of Noncoding RNAs in Lung Cancer Biology and Their Clinical Implications. Genetics research international. 2012; 2012:737416.

19. Tang N, Song WX, Luo J, Haydon RC, He TC. Osteosarcoma development and stem cell differentiation. Clin Orthop Relat Res. 2008; 466:2114-30.

20. Zhu KP, Zhang CL, Shen GQ, Zhu ZS. Long noncoding RNA expression profiles of the doxorubicin-resistant human osteosarcoma cell line MG63/DXR and its parental cell line MG63 as ascertained by microarray analysis. Int J Clin Exp Pathol. 2015; 8:8754-73.

21. Yang Q, Zhang S, Liu H, Wu J, Xu E, Peng B, Jiang Y. Oncogenic role of long noncoding RNA AF118081 in anti-benzo[a]pyrene-trans-7,8-dihydrodiol-9,10-epoxidetransformed 16HBE cells. Toxicol Lett. 2014; 229:430-39.

22. Okazaki Y, Furuno M, Kasukawa T, Adachi J, Bono H, 
Kondo S, Nikaido I, Osato N, Saito R, Suzuki H, Yamanaka I, Kiyosawa H, Yagi K, et al, and FANTOM Consortium, and RIKEN Genome Exploration Research Group Phase I \& II Team. Analysis of the mouse transcriptome based on functional annotation of 60,770 full-length cDNAs. Nature. 2002; 420:563-73.

23. Ponting CP, Oliver PL, Reik W. Evolution and functions of long noncoding RNAs. Cell. 2009; 136:629-41.

24. Derrien T, Johnson R, Bussotti G, Tanzer A, Djebali S, Tilgner H, Guernec G, Martin D, Merkel A, Knowles DG, Lagarde J, Veeravalli L, Ruan X, et al. The GENCODE v7 catalog of human long noncoding RNAs: analysis of their gene structure, evolution, and expression. Genome Res. 2012; 22:1775-89.

25. Shi X, Sun M, Liu H, Yao Y, Song Y. Long non-coding RNAs: a new frontier in the study of human diseases. Cancer Lett. 2013; 339:159-66.

26. Ponjavic J, Ponting CP, Lunter G. Functionality or transcriptional noise? Evidence for selection within long noncoding RNAs. Genome Res. 2007; 17:556-65.

27. Peng ZQ, Lu RB, Xiao DM, Xiao ZM. Increased expression of the lncRNA BANCR and its prognostic significance in human osteosarcoma. Genet Mol Res. 2016; 15:15.

28. Mercer TR, Dinger ME, Mattick JS. Long non-coding RNAs: insights into functions. Nat Rev Genet. 2009; 10:155-59.

29. Li Z, Shen J, Chan MT, Wu WK. TUG1: a pivotal oncogenic long non-coding RNA of human cancers. Cell Prolif. 2016; 49:471-75.

30. Gupta RA, Shah N, Wang KC, Kim J, Horlings HM, Wong DJ, Tsai MC, Hung T, Argani P, Rinn JL, Wang Y, Brzoska P, Kong B, et al. Long non-coding RNA HOTAIR reprograms chromatin state to promote cancer metastasis. Nature. 2010; 464:1071-76.

31. Poliseno L, Salmena L, Zhang J, Carver B, Haveman WJ, Pandolfi PP. A coding-independent function of gene and pseudogene mRNAs regulates tumour biology. Nature. 2010; 465:1033-38.

32. Zhang H, Chen Z, Wang X, Huang Z, He Z, Chen Y. Long non-coding RNA: a new player in cancer. J Hematol Oncol. 2013; 6:37.

33. Schmitt AM, Chang HY. Long Noncoding RNAs in Cancer Pathways. Cancer Cell. 2016; 29:452-63.

34. Malek E, Jagannathan S, Driscoll JJ. Correlation of long non-coding RNA expression with metastasis, drug resistance and clinical outcome in cancer. Oncotarget. 2014; 5:8027-38. doi: 10.18632/oncotarget.2469

35. Xing D, Liang JQ, Li Y, Lu J, Jia HB, Xu LY, Ma XL. Identification of long noncoding RNA associated with osteoarthritis in humans. Orthop Surg. 2014; 6:288-93.

36. Li JP, Liu LH, Li J, Chen Y, Jiang XW, Ouyang YR, Liu YQ, Zhong H, Li H, Xiao T. Microarray expression profile of long noncoding RNAs in human osteosarcoma. Biochem Biophys Res Commun. 2013; 433:200-06.
37. Sang H, Liu H, Xiong P, Zhu M. Long non-coding RNA functions in lung cancer. Tumour Biol. 2015; 36:4027-37.

38. Liu H, Li J, Koirala P, Ding X, Chen B, Wang Y, Wang Z, Wang C, Zhang X, Mo YY. Long non-coding RNAs as prognostic markers in human breast cancer. Oncotarget. 2016; 7:20584-96. doi: 10.18632/oncotarget.7828

39. Sun W, Yang Y, Xu C, Xie Y, Guo J. Roles of long noncoding RNAs in gastric cancer and their clinical applications. J Cancer Res Clin Oncol. 2016; 142:2231-37.

40. Malih S, Saidijam M, Malih N. A brief review on long noncoding RNAs: a new paradigm in breast cancer pathogenesis, diagnosis and therapy. Tumour Biol. 2016; 37:1479-85.

41. Wang LL. Biology of osteogenic sarcoma. Cancer J. 2005; 11:294-305.

42. Jones KB, Salah Z, Del Mare S, Galasso M, Gaudio E, Nuovo GJ, Lovat F, LeBlanc K, Palatini J, Randall RL, Volinia S, Stein GS, Croce CM, et al. miRNA signatures associate with pathogenesis and progression of osteosarcoma. Cancer Res. 2012; 72:1865-77.

43. Cong M, Li J, Jing R, Li Z. Long non-coding RNA tumor suppressor candidate 7 functions as a tumor suppressor and inhibits proliferation in osteosarcoma. Tumour Biol. 2016; 37:9441-50.

44. Zhao H, Hou W, Tao J, Zhao Y, Wan G, Ma C, Xu H. Upregulation of IncRNA HNF1A-AS1 promotes cell proliferation and metastasis in osteosarcoma through activation of the $\mathrm{Wnt} / \beta$-catenin signaling pathway. Am J Transl Res. 2016; 8:3503-12.

45. Ruan W, Wang P, Feng S, Xue Y, Li Y. Long non-coding RNA small nucleolar RNA host gene 12 (SNHG12) promotes cell proliferation and migration by upregulating angiomotin gene expression in human osteosarcoma cells. Tumour Biol. 2016; 37:4065-73.

46. Yin Z, Ding H, He E, Chen J, Li M. Overexpression of long non-coding RNA MFI2 promotes cell proliferation and suppresses apoptosis in human osteosarcoma. Oncol Rep. 2016; 36:2033-40.

47. Qian M, Yang X, Li Z, Jiang C, Song D, Yan W, Liu T, Wu Z, Kong J, Wei H, Xiao J. P50-associated COX-2 extragenic RNA (PACER) overexpression promotes proliferation and metastasis of osteosarcoma cells by activating COX-2 gene. Tumour Biol. 2016; 37:3879-86.

48. Liu C, Lin J. Long noncoding RNA ZEB1-AS1 acts as an oncogene in osteosarcoma by epigenetically activating ZEB1. Am J Transl Res. 2016; 8:4095-105.

49. Khalil AM, Guttman M, Huarte M, Garber M, Raj A, Rivea Morales D, Thomas K, Presser A, Bernstein BE, van Oudenaarden A, Regev A, Lander ES, Rinn JL. Many human large intergenic noncoding RNAs associate with chromatin-modifying complexes and affect gene expression. Proc Natl Acad Sci USA. 2009; 106:11667-72.

50. Zhang Q, Geng PL, Yin P, Wang XL, Jia JP, Yao J. Down-regulation of long non-coding RNA TUG1 inhibits 
osteosarcoma cell proliferation and promotes apoptosis. Asian Pac J Cancer Prev. 2013; 14:2311-15.

51. Xie CH, Cao YM, Huang Y, Shi QW, Guo JH, Fan ZW, Li JG, Chen BW, Wu BY. Long non-coding RNA TUG1 contributes to tumorigenesis of human osteosarcoma by sponging miR-9-5p and regulating POU2F1 expression. Tumour Biol. 2016; 37:15031-41.

52. Ji P, Diederichs S, Wang W, Böing S, Metzger R, Schneider PM, Tidow N, Brandt B, Buerger H, Bulk E, Thomas M, Berdel WE, Serve H, Müller-Tidow C. MALAT-1, a novel noncoding RNA, and thymosin beta4 predict metastasis and survival in early-stage non-small cell lung cancer. Oncogene. 2003; 22:8031-41.

53. Taniguchi M, Fujiwara K, Nakai Y, Ozaki T, Koshikawa N, Toshio K, Kataba M, Oguni A, Matsuda H, Yoshida Y, Tokuhashi Y, Fukuda N, Ueno T, et al. Inhibition of malignant phenotypes of human osteosarcoma cells by a gene silencer, a pyrrole-imidazole polyamide, which targets an E-box motif. FEBS Open Bio. 2014; 4:328-34.

54. Dong Y, Liang G, Yuan B, Yang C, Gao R, Zhou X. MALAT1 promotes the proliferation and metastasis of osteosarcoma cells by activating the PI3K/Akt pathway. Tumour Biol. 2015; 36:1477-86.

55. Cai X, Liu Y, Yang W, Xia Y, Yang C, Yang S, Liu X. Long noncoding RNA MALAT1 as a potential therapeutic target in osteosarcoma. J Orthop Res. 2016; 34:932-41.

56. Luo W, He H, Xiao W, Liu Q, Deng Z, Lu Y, Wang Q, Zheng Q, Li Y. MALAT1 promotes osteosarcoma development by targeting TGFA via MIR376A. Oncotarget. 2016; 7:54733-43. doi: 10.18632/oncotarget.10752

57. Jiang X, Yan Y, Hu M, Chen X, Wang Y, Dai Y, Wu D, Wang Y, Zhuang Z, Xia H. Increased level of H19 long noncoding RNA promotes invasion, angiogenesis, and stemness of glioblastoma cells. J Neurosurg. 2016; 124:129-36.

58. Luo M, Li Z, Wang W, Zeng Y, Liu Z, Qiu J. Long noncoding RNA H19 increases bladder cancer metastasis by associating with EZH2 and inhibiting E-cadherin expression. Cancer Lett. 2013; 333:213-21.

59. Ratajczak MZ, Shin DM, Schneider G, Ratajczak J, Kucia M. Parental imprinting regulates insulin-like growth factor signaling: a Rosetta Stone for understanding the biology of pluripotent stem cells, aging and cancerogenesis. Leukemia. 2013; 27:773-79.

60. Chan LH, Wang W, Yeung W, Deng Y, Yuan P, Mak KK. Hedgehog signaling induces osteosarcoma development through Yap1 and H19 overexpression. Oncogene. 2014; 33:4857-66.

61. He P, Zhang Z, Huang G, Wang H, Xu D, Liao W, Kang Y. miR-141 modulates osteoblastic cell proliferation by regulating the target gene of lncRNA H19 and lncRNA H19-derived miR-675. Am J Transl Res. 2016; 8:1780-88.

62. Wang B, Su Y, Yang Q, Lv D, Zhang W, Tang K, Wang H, Zhang R, Liu Y. Overexpression of Long Non-Coding
RNA HOTAIR Promotes Tumor Growth and Metastasis in Human Osteosarcoma. Mol Cells. 2015; 38:432-40.

63. Zhang Z, Cheng J, Wu Y, Qiu J, Sun Y, Tong X. LncRNA HOTAIR controls the expression of Rab22a by sponging miR-373 in ovarian cancer. Mol Med Rep. 2016; 14:246572.

64. Yang L, Zhang X, Li H, Liu J. The long noncoding RNA HOTAIR activates autophagy by upregulating ATG3 and ATG7 in hepatocellular carcinoma. Mol Biosyst. 2016; 12:2605-12.

65. Wang R, Chen X, Xu T, Xia R, Han L, Chen W, De W, Shu Y. MiR-326 regulates cell proliferation and migration in lung cancer by targeting phox $2 \mathrm{a}$ and is regulated by HOTAIR. Am J Cancer Res. 2016; 6:173-86.

66. Milevskiy MJ, Al-Ejeh F, Saunus JM, Northwood KS, Bailey PJ, Betts JA, McCart Reed AE, Nephew KP, Stone A, Gee JM, Dowhan DH, Dray E, Shewan AM, et al. Long-range regulators of the lncRNA HOTAIR enhance its prognostic potential in breast cancer. Hum Mol Genet. 2016; 25:3269-83.

67. Zhang J, Zhang P, Wang L, Piao HL, Ma L. Long noncoding RNA HOTAIR in carcinogenesis and metastasis. Acta Biochim Biophys Sin (Shanghai). 2014; 46:1-5.

68. Tsai MC, Manor O, Wan Y, Mosammaparast N, Wang JK, Lan F, Shi Y, Segal E, Chang HY. Long noncoding RNA as modular scaffold of histone modification complexes. Science. 2010; 329:689-93.

69. Zhou Q, Chen F, Fei Z, Zhao J, Liang Y, Pan W, Liu X, Zheng D. Genetic variants of lncRNA HOTAIR contribute to the risk of osteosarcoma. Oncotarget. 2016; 7:19928-34. doi: 10.18632/oncotarget.7957

70. Pasic I, Shlien A, Durbin AD, Stavropoulos DJ, Baskin B, Ray PN, Novokmet A, Malkin D. Recurrent focal copynumber changes and loss of heterozygosity implicate two noncoding RNAs and one tumor suppressor gene at chromosome 3q13.31 in osteosarcoma. Cancer Res. 2010; 70:160-71.

71. Liu Q, Huang J, Zhou N, Zhang Z, Zhang A, Lu Z, Wu F, Mo YY. LncRNA loc285194 is a p53-regulated tumor suppressor. Nucleic Acids Res. 2013; 41:4976-87.

72. Ritter J, Bielack SS. Osteosarcoma. Ann Oncol. 2010 (Suppl 7); 21:vii320-25.

73. Hughes DP. Strategies for the targeted delivery of therapeutics for osteosarcoma. Expert Opin Drug Deliv. 2009; 6:1311-21.

74. Wang W, Xing C. Upregulation of long noncoding RNA ZFAS1 predicts poor prognosis and prompts invasion and metastasis in colorectal cancer. Pathol Res Pract. 2016; 212:690-95.

75. Deng QJ, Xie LQ, Li H. Overexpressed MALAT1 promotes invasion and metastasis of gastric cancer cells via increasing EGFL7 expression. Life Sci. 2016; 157:38-44.

76. Peng L, Yuan X, Jiang B, Tang Z, Li GC. LncRNAs: key players and novel insights into cervical cancer. Tumour 
Biol. 2016; 37:2779-88.

77. Zhang CL, Zhu KP, Shen GQ, Zhu ZS. A long non-coding RNA contributes to doxorubicin resistance of osteosarcoma. Tumour Biol. 2016; 37:2737-48.

78. Sun XH, Yang LB, Geng XL, Wang R, Zhang ZC. Increased expression of IncRNA HULC indicates a poor prognosis and promotes cell metastasis in osteosarcoma. Int J Clin Exp Pathol. 2015; 8:2994-3000.

79. Uzan VR, Lengert A, Boldrini É, Penna V, ScapulatempoNeto C, Scrideli CA, Filho AP, Cavalcante CE, de Oliveira CZ, Lopes LF, Vidal DO. High Expression of HULC Is Associated with Poor Prognosis in Osteosarcoma Patients. PLoS One. 2016; 11:e0156774.

80. Chen F, Mo J, Zhang L. Long noncoding RNA BCAR4 promotes osteosarcoma progression through activating GLI2-dependent gene transcription. Tumour Biol. 2016; 37:13403-12.

81. Li W, Xie P and Ruan WH. Overexpression of lncRNA UCA1 promotes osteosarcoma progression and correlates with poor prognosis. Journal of bone oncology. 2016; 5:8085.

82. Sun J, Wang X, Fu C, Wang X, Zou J, Hua H, Bi Z. Long noncoding RNA FGFR3-AS1 promotes osteosarcoma growth through regulating its natural antisense transcript FGFR3. Mol Biol Rep. 2016; 43:427-36.

83. Li F, Cao L, Hang D, Wang F, Wang Q. Long non-coding RNA HOTTIP is up-regulated and associated with poor prognosis in patients with osteosarcoma. Int J Clin Exp Pathol. 2015; 8:11414-20.

84. Lipovich L, Johnson R and Lin CY. MacroRNA underdogs in a microRNA world: evolutionary, regulatory, and biomedical significance of mammalian long non-proteincoding RNA. Biochimica et biophysica acta. 2010; 1799:597-615.

85. Tian ZZ, Guo XJ, Zhao YM, Fang Y. Decreased expression of long non-coding RNA MEG3 acts as a potential predictor biomarker in progression and poor prognosis of osteosarcoma. Int J Clin Exp Pathol. 2015; 8:15138-42.

86. Flockhart RJ, Webster DE, Qu K, Mascarenhas N, Kovalski J, Kretz M, Khavari PA. BRAFV600E remodels the melanocyte transcriptome and induces BANCR to regulate melanoma cell migration. Genome Res. 2012; 22:1006-14.

87. Ma B, Li M, Zhang L, Huang M, Lei JB, Fu GH, Liu CX, Lai QW, Chen QQ, Wang YL. Upregulation of long non-coding RNA TUG1 correlates with poor prognosis and disease status in osteosarcoma. Tumour Biol. 2016; 37:4445-55.

88. Xia WK, Lin QF, Shen D, Liu ZL, Su J, Mao WD. Clinical implication of long noncoding RNA $91 \mathrm{H}$ expression profile in osteosarcoma patients. Onco Targets Ther. 2016; 9:4645-52.

89. Gao KT, Lian D. Long non-coding RNA MALAT1 is an independent prognostic factor of osteosarcoma. Eur Rev Med Pharmacol Sci. 2016; 20:3561-65.
90. Jaffe N, Patel SR, Benjamin RS. Chemotherapy in osteosarcoma. Basis for application and antagonism to implementation; early controversies surrounding its implementation. Hematol Oncol Clin North Am. 1995; 9:825-40.

91. Takahashi S, Kamiyama T, Tomaru U, Ishizu A, Shida T, Osaka M, Sato Y, Saji Y, Ozaki M, Todo S. Frequency and pattern of expression of the stem cell marker CD133 have strong prognostic effect on the surgical outcome of colorectal cancer patients. Oncol Rep. 2010; 24:1201-12.

92. Ailles LE, Weissman IL. Cancer stem cells in solid tumors. Curr Opin Biotechnol. 2007; 18:460-66.

93. Siclari VA, Qin L. Targeting the osteosarcoma cancer stem cell. J Orthop Surg. 2010; 5:78.

94. Wang Y, Yao J, Meng H, Yu Z, Wang Z, Yuan X, Chen H, Wang A. A novel long non-coding RNA, hypoxia-inducible factor- $2 \alpha$ promoter upstream transcript, functions as an inhibitor of osteosarcoma stem cells in vitro. Mol Med Rep. 2015; 11:2534-40.

95. He H, Ni J, Huang J. Molecular mechanisms of chemoresistance in osteosarcoma (Review). Oncol Lett. 2014; 7:1352-62. Review

96. Broxterman HJ, Gotink KJ and Verheul HM. Understanding the causes of multidrug resistance in cancer: a comparison of doxorubicin and sunitinib. Drug resistance updates. 2009; 12:114-126.

97. Cao B, Li M, Zha W, Zhao Q, Gu R, Liu L, Shi J, Zhou J, Zhou F, Wu X, Wu Z, Wang G, Aa J. Metabolomic approach to evaluating adriamycin pharmacodynamics and resistance in breast cancer cells. Metabolomics. 2013; 9:960-73.

98. Townsend DM, Tew KD. The role of glutathione-Stransferase in anti-cancer drug resistance. Oncogene. 2003; 22:7369-75.

99. Bertino JR. Karnofsky memorial lecture. Ode to methotrexate. J Clin Oncol. 1993; 11:5-14.

100. Fujii H, Honoki K, Tsujiuchi T, Kido A, Yoshitani K, Takakura Y. Sphere-forming stem-like cell populations with drug resistance in human sarcoma cell lines. Int $\mathbf{J}$ Oncol. 2009; 34:1381-86.

101. Martins-Neves SR, Lopes AO, do Carmo A, Paiva AA, Simões PC, Abrunhosa AJ, Gomes CM. Therapeutic implications of an enriched cancer stem-like cell population in a human osteosarcoma cell line. BMC Cancer. 2012; 12:139.

102. Meric-Bernstam F, Gonzalez-Angulo AM. Targeting the mTOR signaling network for cancer therapy. J Clin Oncol. 2009; 27:2278-87.

103. Gougelet A, Pissaloux D, Besse A, Perez J, Duc A, Dutour A, Blay JY, Alberti L. Micro-RNA profiles in osteosarcoma as a predictive tool for ifosfamide response. Int $\mathrm{J}$ Cancer. 2011; 129:680-90.

104. Song B, Wang Y, Xi Y, Kudo K, Bruheim S, Botchkina GI, Gavin E, Wan Y, Formentini A, Kornmann M, Fodstad O, 
$\mathrm{Ju}$ J. Mechanism of chemoresistance mediated by miR-140 in human osteosarcoma and colon cancer cells. Oncogene. 2009; 28:4065-74.

105. Asada N, Tsuchiya H, Tomita K. De novo deletions of p53 gene and wild-type p53 correlate with acquired cisplatinresistance in human osteosarcoma OST cell line. Anticancer Res. 1999; 19:5131-37.

106. Chao DT, Korsmeyer SJ. BCL-2 family: regulators of cell death. Annu Rev Immunol. 1998; 16:395-419.

107. Wang Y, Zhang L, Zheng X, Zhong W, Tian X, Yin B, Tian K, Zhang W. Long non-coding RNA LINC00161 sensitises osteosarcoma cells to cisplatin-induced apoptosis by regulating the miR-645-IFIT2 axis. Cancer Lett. 2016; 382:137-46.

108. Xie H, Zhu D, Xu C, Zhu H, Chen P, Li H, Liu X, Xia Y, Tang W. Long none coding RNA HOTTIP/HOXA13 act as synergistic role by decreasing cell migration and proliferation in Hirschsprung disease. Biochem Biophys Res Commun. 2015; 463:569-74.

109. Li Z, Zhao L, Wang Q. Overexpression of long non-coding RNA HOTTIP increases chemoresistance of osteosarcoma cell by activating the Wnt/ $\beta$-catenin pathway. Am J Transl Res. 2016; 8:2385-93.

110. Fang D, Yang H, Lin J, Teng Y, Jiang Y, Chen J, Li Y. $17 \beta$-estradiol regulates cell proliferation, colony formation, migration, invasion and promotes apoptosis by upregulating miR-9 and thus degrades MALAT-1 in osteosarcoma cell MG-63 in an estrogen receptor-independent manner. Biochem Biophys Res Commun. 2015; 457:500-06.

111. Zhang Y, Song L, Cai L, Wei R, Hu H, Jin W. Effects of baicalein on apoptosis, cell cycle arrest, migration and invasion of osteosarcoma cells. Food Chem Toxicol. 2013; 53:325-33.

112. McMaster JH, Scranton PE Jr, Drash AL. Growth and hormone control mechanisms in osteosarcoma. Evidence for a new therapeutic approach. Clin Orthop Relat Res. 1975; 106:366-76. 